\title{
Detection of near-surface reinforcement in concrete components with ultrasound
}

\author{
Sarah Vonk $^{1, *}$, and Alexander Taffe ${ }^{1}$ \\ ${ }^{1}$ HTW Berlin - University of Applied Sciences Berlin, Non-destructive Testing in Civil Engineering Department, 12459 Berlin
}

\begin{abstract}
Ultrasonic testing of concrete has grown in importance considerably in recent years in non-destructive testing in civil engineering (NDT-CE). In the past, the main focus was on the imaging of the internal construction of steel and prestressed concrete components. On the other hand, comparatively little attention was paid to the location of near-surface reinforcement and concrete cover measurement. In this research, it is shown to what extent ultrasound is suitable for the detection of near-surface reinforcement in addition to magnetic inductive methods. The measurements were carried out with the newly developed Pundit 250 Array from the company Proceq and with the measuring devices of the company Acsys, the A1220 Monolith and the A1040 Mira. The ultrasound data was analysed with the vendor-independent software InterSAFT of the University of Kassel. Systematic investigations were carried out on test specimens with a variety on the concrete cover, the diameter of the reinforcement and the reinforcement ratio in the form of mesh reinforcement close to the surface. The detectability and accuracy of the concrete cover were set in relation to the concrete cover, wavelength and reinforcement diameter, with the result that more detailed rules for the detection of reinforcement are formulated for the user, instead of the known $\lambda / 2$-criterion.
\end{abstract}

\section{Introduction}

In the past, ultrasonic testing of concrete has focused on the imaging of the internal construction of reinforced and prestressed concrete structures. The detection of nearsurface reinforcement and concrete cover measurement received relatively little attention.

Until now, the main inspection task for ultrasound was the detection of prestressing steel. However, the detection of reinforcement will gain in importance with the engineering structures currently being built. Magnetic inductive methods reach their limits in RC (reinforced concrete) structures with large concrete covers. With increasing concrete cover, double bars cannot be clearly separated from each other and the diameter of the reinforcement must be known in this process for an exact result. Taffe demonstrates quantitatively in [1] that a reliable detection of the reinforcement with magnetical methods is only possible to a depth of $6 \mathrm{~cm}$. Consequently, alternative investigations in the field of detection of near-surface reinforcement and their accuracy of concrete cover by other means are needed.

The aim of this research was to obtain reliable statements on the suitability of ultrasound for the detection of near-surface reinforcement. It was researched from which depth ultrasonic can represent an alternative to the magnetic inductive methods. For this purpose, it is considered whether a detection is possible and what accuracies can be achieved in the concrete cover measurement. In addition, the detectability of the reinforcement in relation to the wavelength, concrete cover and reinforcement diameter were set.

One of the outcomes at the end was a list of application instructions for imaging of reinforcement bars and the specification of the often applied $\lambda / 2$-criterion. The NDT-CE procedures are only useful for the users, if the results are accurate and therefore reliable. This research with the possibilities and limitations of ultrasound makes a contribution for this purpose.

\section{Preparation of the investigation}

\subsection{Specimens}

Investigations were carried out on four different specimens with different reinforcement diameters, reinforcement ratio and a variety of concrete covers.

Two of the four specimens, Betonprisma 1 and 2, were already present from previous research. The other two specimens, HTW-TK1 and TK2, were planned and built as a part of this research. The specimens are summarised in regard of the varied parameters in Table 1.

During the construction of the new specimens, HTW TK-1 and HTW TK-2, special attention was paid to the dimensionally accurate manufacturing. For example, holes were drilled in the formwork panels and thus the reinforcement was placed exactly in the formwork body. In addition, the reinforcement was additionally fixed with screws on the outer skin of the formwork panels, thus that 
the exact position was not able to change by moving the formwork or during concreting (Fig. 1). While in construction practice, the orientation of the ribs of the reinforcement is insignificant, the reinforcing bars were placed with the rib centre upwards, in order to obtain a uniform reflection of the waves and thus to receive better ultrasonic signals. The maximum deviation of the dimensional accuracy of the specimen amounts to a maximum of $\pm 0,5 \mathrm{~mm}$.

Table 1: summary of the specimen's parameters.

\begin{tabular}{|c|c|c|c|c|}
\hline & $\begin{array}{c}\text { test } \\
\text { specimen } \\
1\end{array}$ & $\begin{array}{c}\text { test } \\
\text { specimen } \\
2\end{array}$ & $\begin{array}{c}\text { test } \\
\text { specimen } \\
3\end{array}$ & $\begin{array}{c}\text { test } \\
\text { specimen } \\
4\end{array}$ \\
\hline name & $\begin{array}{l}\text { Beton- } \\
\text { prisma } 1\end{array}$ & $\begin{array}{c}\text { Beton- } \\
\text { prisma } 2\end{array}$ & HTW-TK1 & HTW-TK2 \\
\hline $\begin{array}{l}\text { reinforcing } \\
\text { bars }\end{array}$ & $15 \varnothing 8 \mathrm{~mm}$ & $\begin{array}{c}15 \varnothing 16 \\
\mathrm{~mm}\end{array}$ & $8 \varnothing 12 \mathrm{~mm}$ & $8 \varnothing 2 \mathrm{~mm}$ \\
\hline $\begin{array}{l}\text { steel fabric } \\
\text { mats }\end{array}$ & \multicolumn{2}{|c|}{-} & - & $\begin{array}{c}\text { Q 188, } \\
\text { dimension } \\
\text { between } \\
\text { the aces } \\
\text { of the } \\
\text { mesh bars } \\
15 \mathrm{~cm}, \\
\varnothing 6 \mathrm{~mm}\end{array}$ \\
\hline $\begin{array}{l}\text { minimum } \\
\text { concrete } \\
\text { cover } \\
\text { dimension } \\
{[\mathrm{mm}]}\end{array}$ & \multicolumn{2}{|c|}{20} & 20 & 40 \\
\hline $\begin{array}{l}\text { maximum } \\
\text { concrete } \\
\text { cover } \\
\text { dimension } \\
{[\mathrm{mm}]}\end{array}$ & \multicolumn{2}{|c|}{100} & 165 & 190 \\
\hline $\begin{array}{l}\text { concrete } \\
\text { cover } \\
\text { dimensions } \\
{[\mathrm{mm}]}\end{array}$ & \multicolumn{2}{|c|}{$20 / 40 / 60 / 80 / 100$} & $\begin{array}{c}20-90 \\
95-165 \\
\text { with } 10 \\
\text { mm steps }\end{array}$ & $\begin{array}{c}40-190 \\
\text { with } \\
10 \mathrm{~mm} \\
\text { steps }\end{array}$ \\
\hline $\begin{array}{l}\text { component } \\
\text { thickness } \\
\text { [cm] }\end{array}$ & \multicolumn{2}{|c|}{20} & 19,7 & 24,2 \\
\hline $\begin{array}{l}\text { component } \\
\text { length[m] }\end{array}$ & \multicolumn{2}{|c|}{1,50} & 1,45 & 1,45 \\
\hline $\begin{array}{l}\text { component } \\
\text { width }[\mathrm{cm}]\end{array}$ & \multicolumn{2}{|c|}{30} & 50 & 50 \\
\hline
\end{tabular}

\subsection{Ultrasonic devices}

For the measurements three different ultrasonic devices were used:

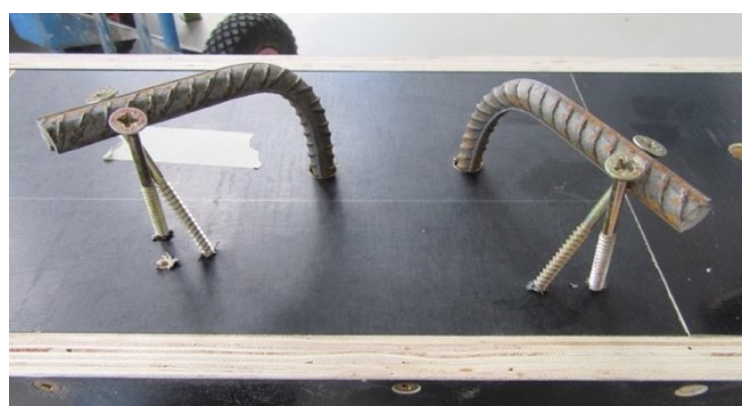

Fig. 1. fixing the reinforcement with screws, orientation of the rib center upwards.
- $\quad$ the Pundit 250 Array, Proceq

- the A1220 Monolith, Acsys

- the A1040 Mira, Acsys

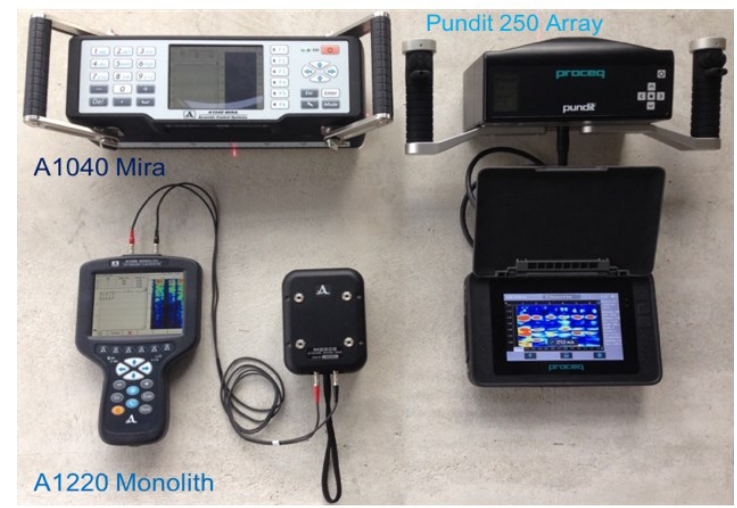

Fig. 2. ultrasonic devices.

The A1220 Monolith is a transmitter-receiver transducer consisting of six blocks, each containing four single dry-point-contact transducers (DPC). 12 of the 24 DPC are grouped into a transmitter unit and 12 DPC are grouped into a receiver unit. The Pundit 250 Array and the A1040 Mira are phased arrays. Each DPC can act as a transmitter and also as a transducer. This allows SAFT to record high-resolution images in a short period of time. The phased array initiates the signals multi-static into the device (Fig. 3). Practically this means e.g. for the Pundit 250 Array, that the first module transmits signals and the echoes are received by the remaining seven modules. Subsequently, the second module transmits signals and the modules three through eight receive the echo, but the first module does not receive the echo. Thereafter, the third module transmits signals and the probe modules receive four to eight, but the first and second modules do not receive. This continues until the seventh module is sent and the eighth module is received. A complete cycle consists of 28 A-scans $(7+6+5+4+3+2+1=28)$. Comparatively the A1040 Mira produces 66 A-scans in one shot $(11+10+9+8+7+6+5+4+3+2+1=$ 66).

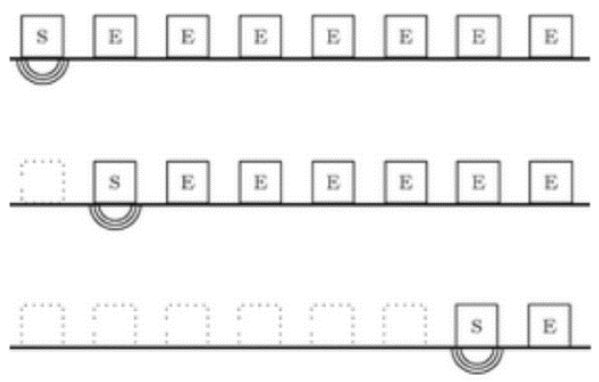

Fig. 3. multi-static principle of the phased array [2]. 
In order to be able to reliably compare the results of the ultrasonic devices, the same settings for the examinations were used. Provided, that the device settings allowed the modification or the same device settings were available.

For the Pundit 250 Array the frequency is preset at $40 \mathrm{kHz}$ and not adjustable. For this reason, a frequency of $40 \mathrm{kHz}$ was also set for the A1220 Monolith and the A1040 Mira. In pre-test measurements, the best results with all three devices were achieved with a gain of $40 \mathrm{~dB}$. The depth-dependent gain (TGC) was not used, because the algorithm of each device is unknown. The pulse voltage is set to $150 \mathrm{~V}$ in the Pundit 250 Array and $200 \mathrm{~V}$ in the Acsys devices and cannot be changed.

The set parameters in the respective devices are summarised in Table 2.

Table 2: summary of the set parameter.

\begin{tabular}{|l|l|l|l|}
\hline & $\begin{array}{l}\text { Pundit } \\
\mathbf{2 5 0} \\
\text { Array }\end{array}$ & $\begin{array}{l}\text { A1220 } \\
\text { Monolith }\end{array}$ & $\begin{array}{l}\text { A1040 } \\
\text { Mira }\end{array}$ \\
\hline offset $\Delta \mathrm{t}$ & $33 \mu \mathrm{s}$ & $24 \mu \mathrm{s}$ & $30 \mu \mathrm{s}$ \\
\hline $\begin{array}{l}\text { position of the } \\
\text { measuring line of the } \\
\text { test specimen }\end{array}$ & centred & centred & centred \\
\hline measuring grid & $3 \mathrm{~cm}$ & $1 \mathrm{~cm}$ & $3 \mathrm{~cm}$ \\
\hline frequency & $40 \mathrm{kHz}$ & $40 \mathrm{kHz}$ & $40 \mathrm{kHz}$ \\
\hline gain & $40 \mathrm{~dB}$ & $40 \mathrm{~dB}$ & $40 \mathrm{~dB}$ \\
\hline $\begin{array}{l}\text { time gain } \\
\text { compensation (TGC) }\end{array}$ & - & - & - \\
\hline pulse voltage & $150 \mathrm{~V}$ & $200 \mathrm{~V}$ & $200 \mathrm{~V}$ \\
\hline
\end{tabular}

\section{Implementation of the measurements}

The ultrasound devices need to be calibrated for the offset and the velocity. As well a measuring grid for the investigations must be determined.

\subsection{Determination of the offset}

The measurand for determining the depth of a reinforcing bar or thickness is the transit time for ultrasonic measurements. In order to determine the transit time correctly, the offset must be determined in advance. This is the time difference between the generation of the signal in the transducer to the actual occurrence in the component.

For the Pundit 250 Array, the offset was determined using a built-in measurement mode that uses the multiple reflections. An offset of $33 \mu \mathrm{s}$ was determined.

The offset for the A1220 Monolith was determined using the method "zero-point-adjustment on several reference bodies" described in leaflet B4 of the German Society for Non-Destructive Testing (DGZfP) [8]. Using this method, an offset of $24 \mu \mathrm{s}$ was defined.

For the A1040 Mira, the offset cannot be determined as for the A1220 Monolith, because the A1220 Monolith is a transmitter-receiver phased array and the A1040 Mira a multi-static phased array. Therefore, the offset for the A1040 Mira was determined experimentally. With the set device settings and the determined velocity of the test specimen HTW-TK1, a measurement was carried out at a reference measuring point on HTW-TK1. Due to the known component thickness and velocity (see chapter 3.2) of the test specimen, the offset could be changed manually in the unit, until the display of the back wall coincided with the existing component thickness. An offset of $30 \mu$ s was determined.

\subsection{Determination of the velocity}

The velocity was first determined with the Pundit 250 Array via the integrated measurement mode "estimate by echo". For this purpose, the component thickness must be known and entered. Then, the velocity is determined with the first multiple reflection. For verification, the velocity was also determined with the A1220 Monolith.

Therefore, fifteen individual measurements were carried out at three different reference-measuring points at the specimens. Subsequently, the respective arithmetic mean was formed and after inserting the transit time and component thickness in equation 1 , the velocities in Table 3 were obtained. Due to the relatively low divergent velocities, a uniform material distribution in both specimens can be assumed.

$$
v=(\mathrm{d} * 2) / \mathrm{t}
$$

Table 3: determined velocities $[\mathrm{m} / \mathrm{s}]$.

\begin{tabular}{|l|l|l|l|l|}
\hline Test specimen & $\begin{array}{l}\text { Beton- } \\
\text { prisma } \\
\text { 1 }\end{array}$ & $\begin{array}{l}\text { Beton- } \\
\text { prisma } \\
\mathbf{2}\end{array}$ & $\begin{array}{l}\text { HTW- } \\
\text { TK1 }\end{array}$ & $\begin{array}{l}\text { HTW- } \\
\text { TK2 }\end{array}$ \\
\hline $\begin{array}{l}\text { Pundit 250 } \\
\text { Array }\end{array}$ & 2733 & 2724 & 2684 & 2680 \\
\hline A1220 Monolith & 2695 & 2703 & 2710 & 2710 \\
\hline \hline arithmetic mean & $\mathbf{2 7 1 4}$ & $\mathbf{2 7 1 3}$ & $\mathbf{2 6 9 7}$ & $\mathbf{2 6 9 5}$ \\
\hline
\end{tabular}

\subsection{Measuring grid}

To define a measuring grid for the Pundit 250 Array, systematic test measurements were performed on Betonprisma 1 and 2. In order to obtain the most significant measurement result, the overlapping function of the transducers was used. Measuring grids of $0 \mathrm{~cm}, 3$ $\mathrm{cm}, 6 \mathrm{~cm}, 9 \mathrm{~cm}, 12 \mathrm{~cm}, 15 \mathrm{~cm}$ and $18 \mathrm{~cm}$ were chosen according to the transducer spacing of $3 \mathrm{~cm}$. It became apparent that good measurement results are achieved with a $3 \mathrm{~cm}$ measuring grid.

Through various research projects, for example in [4, 5], it is known that the most accurate measurements are achieved with a measuring grid of $1 \mathrm{~cm}$ for the A1220 Monolith.

The A1040 Mira experiences meaningful results with a measuring grid of $5 \mathrm{~cm}$ [6]. But since the Pundit 250 Array achieves its optimal measurement results with a measuring grid of $3 \mathrm{~cm}$, a measuring grid of $3 \mathrm{~cm}$ is also selected for the A1040 Mira for a better qualitative comparison.

To increase the measuring accuracy, a heightadjustable wooden beam construction was used. This helped to counteract the fatigue of the tester in order to keep the accuracy constant. The measurement setup is shown for the A1220 Monolith as an example in Figure 4. 


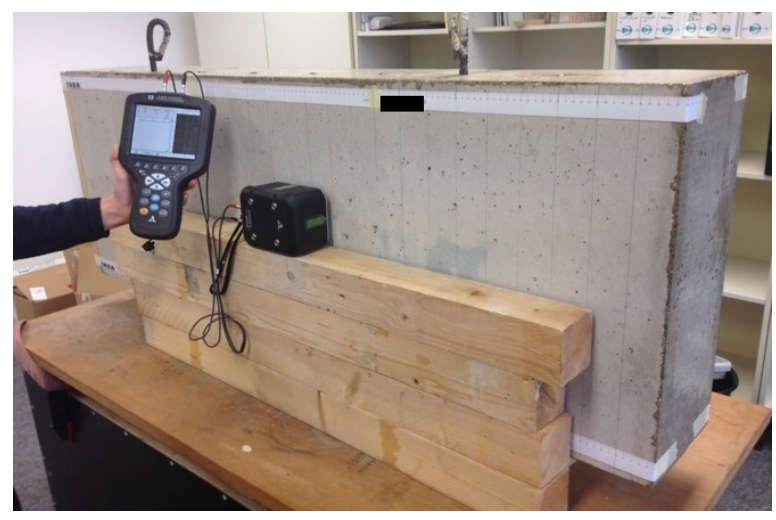

Fig. 4. measuring setup for the A1220 as an example.

To minimize boundary effects, the measurement line is set in the centre of the test specimen. Due to given boundary conditions, such as the fixed dimensions of the wooden beams and the geometry of the probes, the position of the measurement line is not hundred percent centred. The minimum deviation from the centre position has no influence on the results. Rather, a very high measurement accuracy is of great importance for the generation of reliable data.

\section{Evaluation of the measurements}

The ultrasound data of the measurements was imported into the InterSAFT software for evaluation. The basics of the SAFT reconstruction can be found in [7]. The processing of the ultrasound images with the InterSAFT software and the picking of the concrete cover are explained in this chapter.

\subsection{Software InterSAFT}

The software InterSAFT from Dr.-Ing. Klaus Mayer from the University of Kassel is used to evaluate ultrasound data. For the measurements carried out in the context of this research, the software InterSAFT is used as a standardized comparison platform. The InterSAFT software has established itself in the processing of ultrasound data in research and within this research is a need for a uniform comparison platform for the targeted examinations.

In the context of this research the use of ultrasound data in InterSAFT was technically realized for the Pundit 250 Array. A converter based on matlab was developed in cooperation with Dr.-Ing. Klaus Mayer and Proceq.

\subsection{Results of specimen Betonprisma 1}

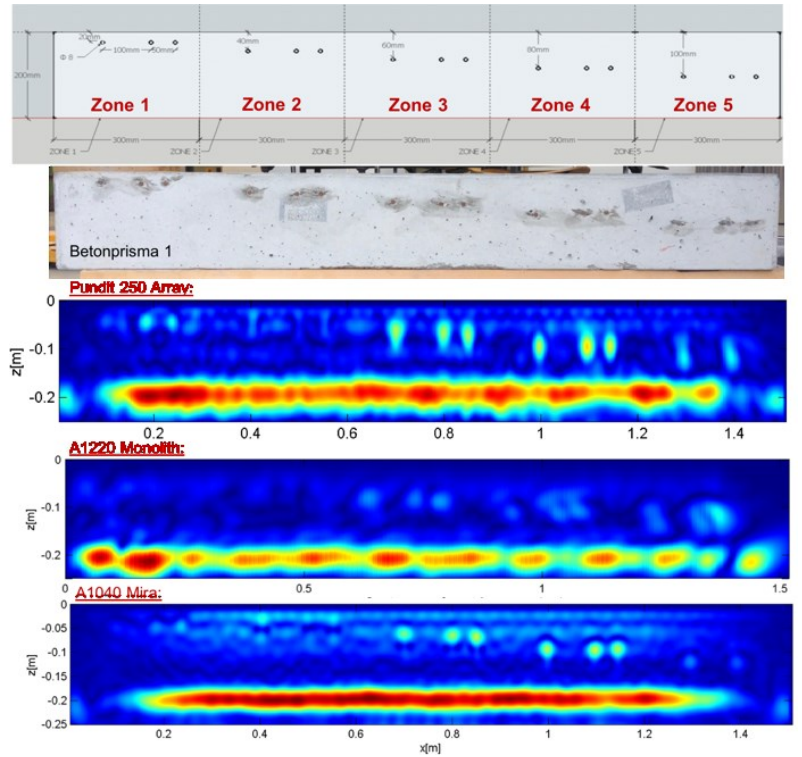

Fig. 5. Betonprisma $1 \mathrm{HTW}$ Berlin - $40 \mathrm{kHz}$ - Pundit 250 Array measuring grid $3 \mathrm{~cm}$ - A1220 Monolith measuring grid $1 \mathrm{~cm}-$ A1040 Mira measuring grid $3 \mathrm{~cm}$.

Fig. 5 displays the Betonsprisma 1 with reinforcing bars $\varnothing 8$, its drawing and the SAFT images of the three ultrasonic devices with a frequency of $40 \mathrm{kHz}$ and a measuring grid of $3 \mathrm{~cm}$.

With the Pundit 250 Array and the A1040 Mira all rebar's of zone 3 and 4 can be clearly detected. The first two reinforcing bar of zone 5 can only be guessed. The A1220 Monolith is not able to clearly detect the rebar's Ø8.

\subsection{Results of specimen Betonprisma 2}

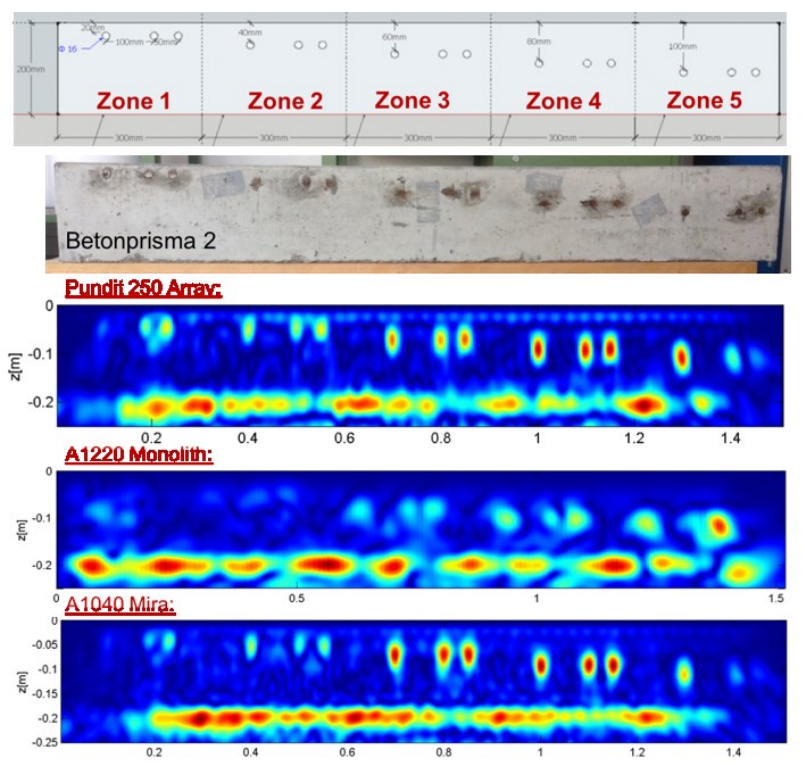

Fig. 6. Betonprisma 2 HTW Berlin - $40 \mathrm{kHz}$ - Pundit 250 Array measuring grid $3 \mathrm{~cm}-\mathrm{A} 1220$ Monolith measuring grid $1 \mathrm{~cm}-$ A1040 Mira measuring grid $3 \mathrm{~cm}$. 
Fig. 6 displays the Betonsprisma 2 with reinforcing bars $Ø 16$. With the Pundit 250 Array and the A1040 Mira all rebar's can be clearly detected. Only the first reinforcing bar of zone 1 and the last reinforcing bar of zone 5 can only be guessed and cannot be detected reliably. This does not indicate a device problem but is due to boundary effects.

With the A1220 Monolith, the reinforcing bars in zone 2 and 3 are clearly detected. In zone 5 , the first rebar of the zone can still be clearly detected, the last two blur into a reflector, which is probably related to the boundary effects as before. The reinforcing bars of Zone 2 and 3 are also to be guessed but cannot be properly defined as a reflector.

In conclusion, rebar's with $\varnothing 16$ can be detected with a concrete cover of minimum $20 \mathrm{~mm}$ with the Pundit 250 Array and the A1040 Mira with a frequency of $40 \mathrm{kHz}$. With the A1220 Monolith and a frequency of $40 \mathrm{kHz}$, the detection of rebar's is only possible with a minimum depth of $60 \mathrm{~mm}$.

\subsection{Results of specimen HTW-TK1}
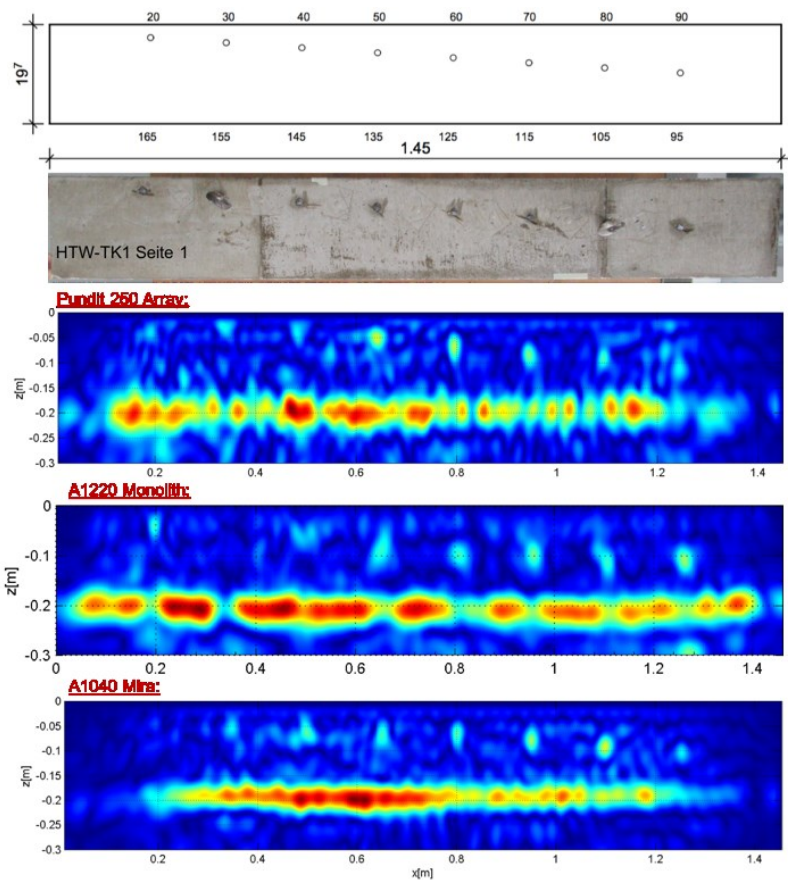

Fig. 7. HTW-TK1 side 1 - $40 \mathrm{kHz}$ - Pundit 250 Array measuring grid $3 \mathrm{~cm}$ - A1220 Monolith measuring grid $1 \mathrm{~cm}$ - A1040 Mira measuring grid $3 \mathrm{~cm}$.

Fig. 7 shows the HTW-TK1 side 1 and its InterSAFT images of the individual devices. HTW-TK1 side 1 is the side on which the concrete cover dimensions of 20 to $90 \mathrm{~mm}$ are in $10 \mathrm{~mm}$ step-wise available. With the Pundit 250 Array and the A1040 Mira all rebar's are detected except the first one. The first reinforcing bar with a concrete cover of $20 \mathrm{~mm}$ can only be guessed. It could be an artefact due to the superposition of surface waves. The last five reinforcing bars were detected with the A1220 Monolith. The second and third rebar were not detected, the first can only be guessed.
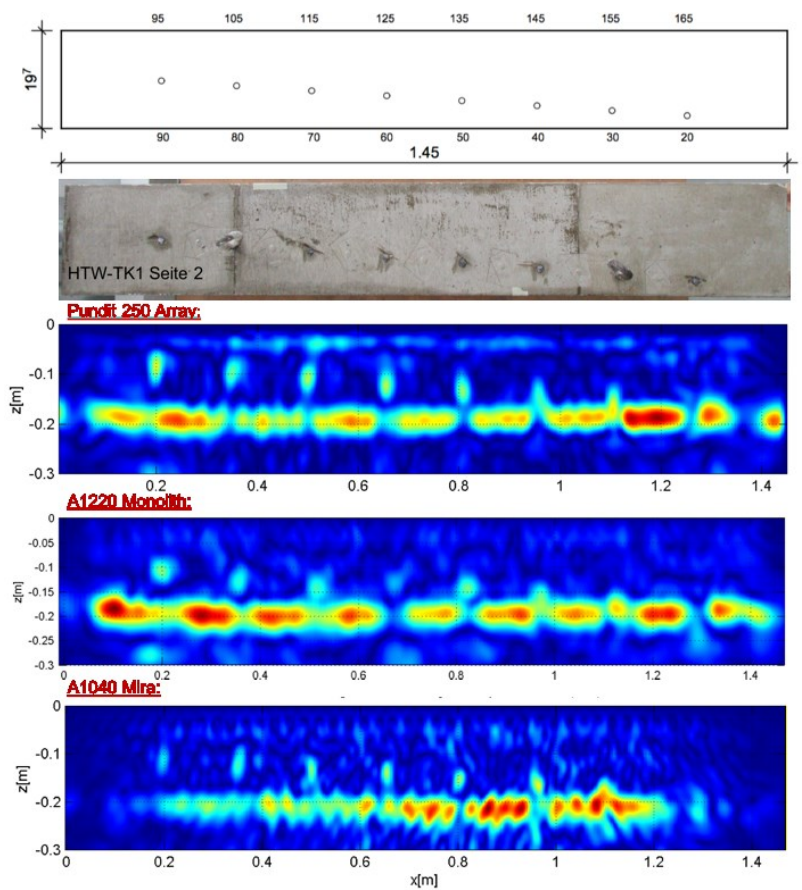

Fig. 8. HTW-TK1 side $240 \mathrm{kHz}$ - Pundit 250 Array measuring grid $3 \mathrm{~cm}$ - A1220 Monolith measuring grid $1 \mathrm{~cm}$ - A1040 Mira measuring grid $3 \mathrm{~cm}$.

Subsequently, the HTW-TK1 was sounded through from side 2. Here, the rebar's are detected with all three ultrasound devices until the penultimate rebar (Fig. 8). The penultimate as well as the last rebar are no longer detected, as both are 20 or $30 \mathrm{~mm}$ too close to the back wall and thus the reflectors are superimposed with the total reflection in air of the back wall.

\subsection{Results of specimen HTW-TK2}
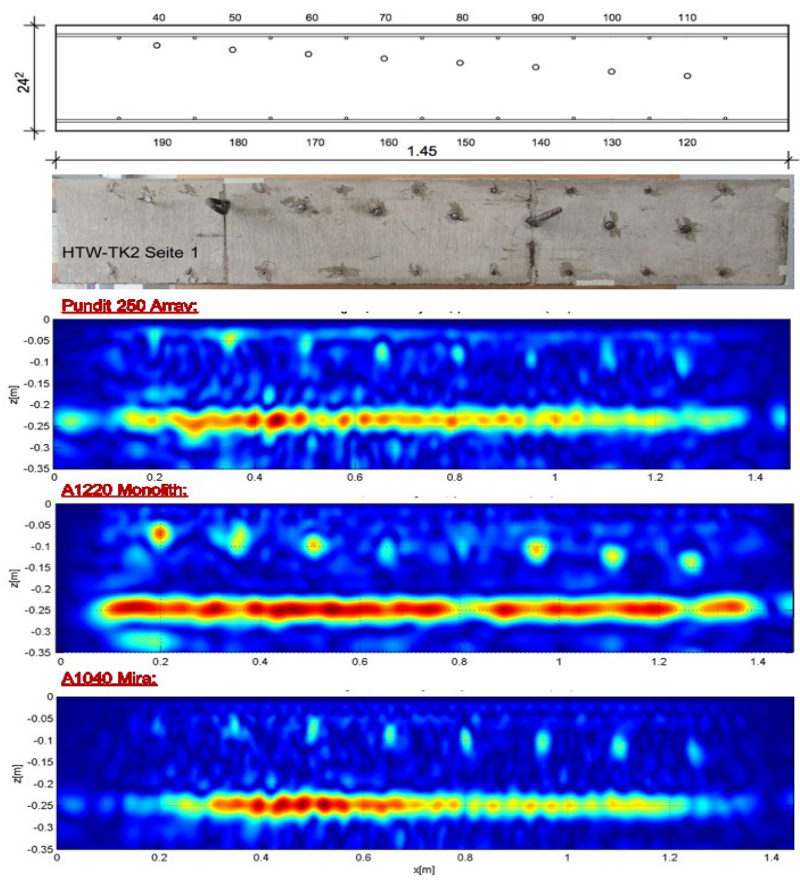

Fig. 9. HTW-TK2 side $140 \mathrm{kHz}$ - Pundit 250 Array measuring grid $3 \mathrm{~cm}$ - A1220 Monolith measuring grid $1 \mathrm{~cm}$ - A1040 Mira measuring grid $3 \mathrm{~cm}$. 
Fig. 9 shows the results of the ultrasound data for the HTW-TK2 page 1 with the near-surface reinforced area as a disruptive effect. The mat simulating the near-surface reinforced area is not detected, because the diameter of the individual rebar's is too small with $\varnothing 6$ and it is too close to the concrete surface $\left(d_{c}=2 \mathrm{~cm}\right)$. With all three devices, the rebar's $\varnothing 12$ can be detected. Only the first rebar cannot be clearly detected with the A1040 Mira.

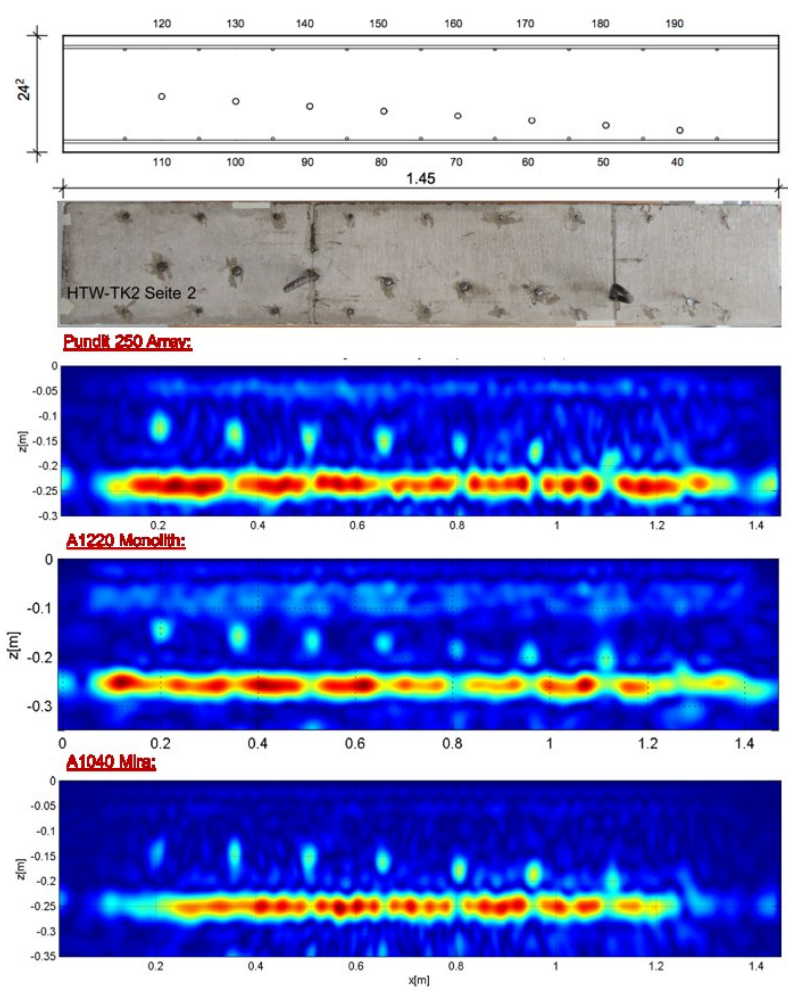

Fig. 10. HTW-TK2 side $240 \mathrm{kHz}$ - Pundit 250 Array measuring grid $3 \mathrm{~cm}$ - A1220 Monolith measuring grid $1 \mathrm{~cm}$ - A1040 Mira measuring grid $3 \mathrm{~cm}$.

At the side 2 of the HTW-TK2 with the concrete coverings of 120 to $190 \mathrm{~mm}$, all the rebar's were detected with all devices except for the last one (Fig. 10). This is due to the fact that the inserted reinforcement mat is located at a distance of $8 \mathrm{~mm}$ directly behind the reinforcing bar and has a small distance of $40 \mathrm{~mm}$ to the back wall. As a result, the reflector of the reinforcing bar is superimposed with the back wall reflection.

\section{Conclusion}

The aim of this research was to investigate whether and to what extent ultrasound is suitable for the detection of near-surface reinforcement as a supplement to magnetic inductive devices. The systematic investigations were evaluated with regard to the limits and possibilities of the reinforcement location and concrete cover measurement as well as to the specification of the $\lambda / 2$-criterion. It must be pointed out that the generated SAFT images and the objective comparability of the ultrasound data are not possible with the respective manufacturer software.

\subsection{Location of reinforcement}

The results of the reinforcement location were evaluated on the basis of a simplified, subjective PoD. It was investigated from which depth ultrasound can be used as an alternative test method to magnetic inductive devices and to what depth the detection is possible. With the Pundit 250 Array and the A1040 Mira, the reinforcing bars $\varnothing 12$ could be detected from $30 \mathrm{~mm}$ concrete cover (Ø16, $20 \mathrm{~mm}$, Betonprisma 2). With the A1220 Monolith a detection was only possible with a concrete cover of $50 \mathrm{~mm}$. Thus, a reliable reinforcement location with all three ultrasonic devices, as stated in previous investigations [8] is only possible with a concrete cover of $50 \mathrm{~mm}$

At depth, all rebar's could be detected up to $180 \mathrm{~mm}$. The deepest rebar of $190 \mathrm{~mm}$ was not detected due to the overlap of the reflectors with the back wall reflection and the near-surface reinforced area. A deeper detection of individual reinforcing bars is quite possible. This has to be tested on a specimen with a larger component thickness and deeper rebar's inserted.

Compared with the near-surface non-reinforced area of the specimen HTW-TK1 to the near-surface reinforced area of the HTW-TK2 in the form of a mat, this did not interfere with the detection of the underlying reinforcement. Accordingly, a view into deeper layers is also denser near-surface reinforcement possible.

\subsection{Concrete Cover}

Afterwards, the accuracy with which the concrete cover in the near-surface region can be determined with the ultrasound method was investigated. Concrete cover dimensions of $30 \ldots 180 \mathrm{~mm}$ in $10 \mathrm{~mm}$ increments and their measuring accuracy were examined. The actual concrete coverings have a maximum difference of $0.5 \mathrm{~mm}$ and the measurement uncertainty is $5 \%$ with maximum deviation on the safe side.

The evaluation [9] revealed the following measurement deviations for the individual devices: With the Pundit 250 Array the concrete coverings can be specified to $\pm 1 \mathrm{~cm}$ and with the A1220 Monolith to $+3 \mathrm{~cm}$ and with the A1040 Mira to $+2 \mathrm{~cm}$ exactly. It has been found that the tendency tends to be that the deeper the reinforcing bars are located, the more accurate the concrete cover has been indicated.

\section{$5.3 \lambda / 2-$ criterion}

In addition, the known $\lambda / 2$-criterion was investigated, whereby with a frequency of $40 \mathrm{kHz}$ and a propagation speed of $2.500 \mathrm{~m} / \mathrm{s}$ objects could only be detected from a size of $3 \mathrm{~cm}$. In this research, however, it was shown that object sizes from $8 \mathrm{~mm}$ with a wavelength of $67 \mathrm{~mm}$, according to the results of the reinforcement location from a depth of $5 \mathrm{~cm}$, can be reliably detected. It has been shown that the $\lambda / 2$-criterion can be extended to $\lambda / 8$ with $\lambda \approx 7 \mathrm{~cm}$. 


\subsection{Limits to other methods}

A reinforcement location by means of ultrasound is possible according to the evaluated investigations from a depth of $5 \mathrm{~cm}$ up to $18 \mathrm{~cm}$. With the magnetic inductive method, a detection of the reinforcing bars is possible only to a depth of $6 \mathrm{~cm} \mathrm{[10].} \mathrm{Thus,} \mathrm{in} \mathrm{terms} \mathrm{of} \mathrm{reinforcement}$ location and concrete coverage measurement, the ultrasonic technique provides an alternative to deeperlevel views where magnetic-inductive techniques have reached their limits. The reinforcement can be detected with a measuring accuracy of $\pm 1 \ldots 3 \mathrm{~cm}$, depending on the device, for the concrete cover measurement. In addition, a view behind high reinforcement ratio for ultrasound is not a problem, which is not possible with magnetic inductive methods. In addition, in the case of the eddy current method in the case of bars that are too close to each other [10], the individual reinforcing bars cannot longer be detected separately, but are recognized as double bars. On the specimen of the Betonprisma 1 and 2, it was identified that the separate detection of closely adjacent reinforcing bars $(\mathrm{a}=5 \mathrm{~cm})$ with ultrasound poses no problem.

\subsection{Practice-oriented instructions for use}

As practical application notes the following points can be adopted:

- detection of reinforcement with ultrasound from $5 \mathrm{~cm}$ to $18 \mathrm{~cm}$, possibly even deeper

- measuring accuracy of the devices in concrete cover measurement:

$$
\begin{aligned}
& >\text { Pundit } 250 \text { Array } \pm 1 \mathrm{~cm} \\
& >\text { A1220 Monolith }+3 \mathrm{~cm} \\
& >\text { A1040 Mira }+2 \mathrm{~cm}
\end{aligned}
$$

- $\quad$ object size to be detected at $40 \mathrm{kHz}$ and a wavelength of $65 \mathrm{~mm}: \lambda / 8 \rightarrow$ object size $\min .8 \mathrm{~mm}$ or $\lambda \approx 7 \mathrm{~cm}$

- The ultrasonic method is suitable as a supplement or in combination with magnetic inductive methods

- no impairment of the ultrasound procedure in areas with close to surface reinforcement

\section{References}

1. Taffe A., B. Jungen; In: Beton- und Stahlbetonbau 111. Untersuchungen zur Genauigkeit von magnetisch induktiven Betondeckungsmessungen. p. 484-495, (2016).

2. Bailler, G. : Abbildung und Analyse von Fehlstellen in Betonbauteilen mittels Ultraschall unter Berücksichtigung von Materialinhomogenitäten. Kassel University Press. Dissertation, Kassel 2014.

3. German Society for Non-Destructive Testing (DGZfP): leaflet B04 - Merkblatt über Ultraschallverfahren zur zerstörungsfreien Prüfung im Bauwesen.self-publishing, Berlin (2018), in print.

4. Feldmann, R., Zoega A., Milmann, B. und Krause M. : Ortung tiefliegender Bewehrung durch Ultraschall mit bildgebender Phasenauswertung. In: DGZfP (Hrsg.); Conference proceedings for the symposium Bauwerksdiagnose 2014, BAM Berlin, 13.-14.02.2014, poster 8, http://www.ndt.net/search/docs.php3?showForm=of $\mathrm{f \& id}=15885$, called on 17.11.2017.

5. Maack, S. : Untersuchungen zum Schallfeldniederfrequenter Ultraschallköpfe für die Anwendung im Bauwesen. BAM (Federal Institute for Material Research and Testing) book series, band 95, Berlin, 2012.

6. Ahmetaj, F. : Beitrag zur bildgebenden Darstellung von Ultraschallmessungen an massigen Bauteilen. masterthesis at Non-destructive Testing in Civil Engineering Department, University of Applied Sciences Berlin, 2017.

7. Schickert, M. : Grundlagen der Ultraschall-SAFTRekonstruktion. In: H.-W. Reinhardt er al.: EchoVerfahren in der zerstörungsfreien Zustandsuntersuchung von Betonbauteilen In: Bergmeister, K., Wörner, J.-D. (Hrsg.); Betonkalender 2007. Bd. 1. Berlin: Ernst \& Sohn, p. 536-543, (2007).

8. Mertens, M. (Hrsg.): Handbuch Bauwerksprüfung Standsicherheit, Verkehrssicherheit, Dauerhaftigkeit. 1. edition. Köln : Rudolf Müller, 2015.

9. Vonk, S.: Bildgebende Darstellung oberflächennaher Bewehrung mit Ultraschall an Beton und Ermittlung der Genauigkeit der Betondeckung. masterthesis at Non-destructive Testing in Civil Engineering Department, University of Applied Sciences Berlin, 2018.

10. Jungen, B.: Quantifizierung von Abweichungen bei Betondeckungsmessverfahren an dicht bewehrten Stahlbetonbauteilen mit magnetisch induktiven Verfahren. masterthesis at Non-destructive Testing in Civil Engineering Department, University of Applied Sciences Berlin, 2015. 